\title{
Clean-up of Extracts for Nitrated Derivatives of Polycyclic Aromatic Hydrocarbons Analyses prior to their Gas Chromatography Determination
}

\author{
Jiří Pryček, ${ }^{*, a}$ Miroslav Ciganek ${ }^{b}$ and Zdeněk Šimek ${ }^{c}$ \\ ${ }^{a}$ Institute of Chemistry and Technology of Environmental Protection, Faculty of Chemistry, \\ Brno University of Technology, 118 Purkynova, 61200 Brno, Czech Republic \\ ${ }^{b}$ Veterinary Research Institute, 70 Hudcova, 62132 Brno, Czech Republic \\ ${ }^{c}$ Research Centre for Environmental Chemistry and Ecotoxicology, Faculty of Science, \\ Masaryk University Brno, 126/3 Kamenice, 62500 Brno, Czech Republic
}

Este estudo focalizou o fracionamento da mistura de hidrocarbonetos policíclicos aromáticos e seus derivados, especialmente derivados nitrados, encontrados no solo e em extratos de poeira de beira de estrada. Foi utilizada cromatografia líquida com coluna de sílica gel aberta. Diferentes volumes de hexano, hexano:diclorometano $(1: 1$ e 4:1, v/v), diclorometano e metanol foram usados para a eluição de frações individuais. O aumento do volume de hexano não foi suficiente para separar completamente uma pequena fração polar da fração aromática. $\mathrm{O}$ aumento do conteúdo de hexano na mistura de eluição melhorou a separação do grupo dos compostos alvos. Extratos de poeira de beira de estrada e do solo foram obtidos pelo uso de um solvente extrator pressurizado com diclorometano como solvente de extração. Os limites de detecção do método variaram de 50 a $220 \mathrm{pg}$ para cada nitro-PAHs, injetado no cromatografo gasoso. Uma quantidade significante de 1-nitropireno foi detectada em amostras reais coletadas próximas ao centro de Brno.

This study was focused on the fractionation of the mixture of polycyclic aromatic hydrocarbons and their derivatives, especially nitrated derivatives, found in soil and roadside dust extracts. Liquid chromatography with an open silica gel bed was used. Different volumes of hexane, hexane:dichloromethane (1:1 and 4:1, v/v), dichloromethane and methanol were used for the elution of individual fractions. Increasing volume of hexane was not sufficient for complete separation of a slightly polar fraction from the aromatic fraction. Increasing content of hexane in the elution mixture improved the separation of the group of target compounds. Soil and roadside dust extracts were obtained by using a pressurised solvent extractor with dichloromethane as the extraction solvent. Detection limits of the method ranged from 50 to $220 \mathrm{pg}$ of individual nitro-PAHs injected into gas chromatograph. A significant amount of 1-nitropyrene was detected in the real samples collected close to the Brno centre.

Keywords: silica gel, fractionation, PAHs, nitro-PAHs, soil, roadside dust

\section{Introduction}

Polycyclic aromatic hydrocarbons (PAHs) and their derivatives are released into the air from diverse sources such as engines, power plants and incinerators. PAHs are also naturally present in crude oil. Derivatives are also formed during photochemical reactions in the atmosphere. ${ }^{1}$

A group of PAHs and their derivatives are toxicologically significant. Their mutagenic or carcinogenic properties are the main risk for human health. ${ }^{2-7}$ These

*e-mail: prycek@email.cz compounds are adsorbed onto roadside dust particles and can be breathed in, potentially causing health problems. They can also be deposited in soils near roads.

Raw organic extracts of environmental samples contain different groups of compounds depending on the extraction method and extraction solvent used. The composition of these extracts is extremely complex. The complexity is caused by the presence of hundreds of aliphatic, aromatic and other compounds. PAHs and their derivatives are present in most cases. The most studied groups of compounds are alkylated derivatives (alkyl-PAHs), nitrated (nitro-PAHs) and oxygenated forms of PAHs (oxy-PAHs). 
The final determination of target compounds can be complicated if there are elevated concentrations of individual compounds present in the sample extract. Additionally, there are problems in determination the derivatives of PAHs in the presence of their parental compounds.

Several extract clean-up steps are necessary to reduce matrix induced signal and to protect GC columns prior to gas chromatography (GC) trace analyses. These procedures are based on the differences in chemical or physical properties of compounds. For example, a former clean up technique is acid-base partitioning. It utilises different acid-base behaviour of compounds in the solution. The disadvantages of this technique is a higher solvent consumption and emulsion formation. ${ }^{8}$ Current clean-up techniques utilise several liquid chromatographic methods especially open column or high performance liquid chromatography (HPLC) $)^{4,7,9-11}$ and solid phase extraction (SPE). ${ }^{11,12}$

The principles of open column liquid chromatography, HPLC and SPE often used for preparation of individual groups of compounds, are based on adsorption and/or partition chromatography on polar or slightly polar adsorbents. The most polar compounds are the most retained ones in this system. The HPLC method has higher separation efficiency, but it is more expensive. Open column chromatography is cheaper and sufficient for the separation of groups of compounds with similar physical properties.

Silica gel and aluminium oxide are the most commonly used adsorbents for open column chromatography. Solvents or their mixtures are used for the elution of compounds or groups of compounds in order of increasing polarity. The nonpolar fraction (alkanes, cycloalkanes) is usually eluted by a nonpolar solvent (pentane, hexane or petroleumether). The aromatic fraction (PAHs, alkylPAHs) is eluted by the mixture of hexane and dichloromethane (DCM). A slightly polar fraction (nitroPAHs, dinitro-PAHs) is eluted by DCM and the polar fraction (oxy-PAHs, alcohols, phthalates) is eluted by the mixture of DCM and polar solvents (acetone, $\mathrm{MeOH}$ ). The pure polar solvents may be used in the last step. ${ }^{13-15}$

The aim of this study was to develop an analytical procedure for the quantitative determination of nitro-PAHs in the presence of PAHs and their derivatives found in roadside dust and soil. Pressurised solvent extraction (PSE) was used for complex extraction of investigated compounds from soil or roadside dust samples. Gas chromatography with mass spectrometry detection (GCMS) was used for the final determination of target compounds. Different fractionation conditions for extract clean-up using open column chromatography on silica gel were studied.

As mentioned in the previous paper, a set of eluents due to their different polarities had to be used for the preanalytical fractionation of extracted analytes. ${ }^{16}$ However, different total volumes of individual solvents and/or mixtures of solvents used for subsequent elution could affect the whole fractionation of analysed compounds in real environmental samples. The effects of the total volume of hexane fraction and solvent ratio in hexane/DCM fraction on fractionation efficiency were investigated.

The effect of different solvents (hexane, cyclohexane and DCM) used for dissolution of dried dichloromethane PSE extracts was demonstrated in a previous paper. ${ }^{16}$ Because DCM was not found as a suitable solvent, hexane and cyclohexane were compared in this work.

\section{Experimental}

\section{Chemicals}

Solid substances of 16 US EPA PAHs, 1-methylnaphthalene, 2-methylnaphthalene, 5-methylchrysene, 2 nitrofluorene, 1-nitropyrene, 9-nitroanthracene, 1-nitronaphthalene, 6-nitrochrysene, 9H-fluorene-9-one, anthracene-9,10-dione and hexachlorobenzene (HCB) were supplied by Sigma-Aldrich (USA). All solvents obtained from Merck (Darmstadt, Germany) were SupraSolv purity (dichloromethane, isooctane, $n$-hexane and methanol) and they were used without any further purification. Cyclohexane p.a. was rectified and its purity was checked on GC-MS. Sodium sulphate p.a. (Onex, Czech Republic), dried at $650{ }^{\circ} \mathrm{C}$ for $1 \mathrm{~h}$ and silica gel 60 (Sigma-Aldrich, USA)-70-230 mesh, activated at $180{ }^{\circ} \mathrm{C}$ for $4 \mathrm{~h}$ were used. Helium (purity 99.999\%, Messer Technogas, Czech Republic) and nitrogen (purity 99.99\%, Linde Technoplyn, Czech Republic) were used as carrier gas and drying gas respectively.

Neat nitro-PAHs were used for the preparation of a calibration solution in isooctane. Single point calibration was used for quantification of nitro-PAH in the samples. Concentration of each nitro-PAHs in this solution was $1 \mu \mathrm{g} \mathrm{mL} \mathrm{m}^{-1}$. Concentration of $\mathrm{HCB}$ in all solutions was $0.476 \mathrm{mg} \mathrm{mL}^{-1}$. This substance was used as an internal standard to eliminate eventual instability of MS detector response.

\section{Sample preparation and extraction}

Soil particles were collected close to a city road (Palackeho, Brno, Czech Republic) and roadside dust was 
collected in the same city from Palackeho/Hradecka interchange shoulder. Samples were air dried at room temperature for one day. Dry samples were sieved to remove particles of $\geq 600 \mu \mathrm{m}$. Sieved samples were homogenised by mixing and kept in $40 \mathrm{~mL}$ glass vials with PTFE/silicon septa wrapped with aluminium foil and stored at $-18^{\circ} \mathrm{C}$ in a freezer.

The extraction of compounds from samples was performed by using a pressurised solvent extractor (FastEx, Unikovo, Czech Republic). About $2 \mathrm{~g}$ of homogenised sample was mixed with $3 \mathrm{~g}$ of anhydrous sodium sulphate to remove any remaining water in the sample. This mixture was extracted using $11 \mathrm{~mL}$ extraction vessel of PSE instrument. The free capacity of the vessel was filled with glass beads of $1 \mathrm{~mm}$ diameter. DCM, at $100^{\circ} \mathrm{C}$ and 14 $\mathrm{MPa}$, in one extraction cycle was used for extraction. Two cycles with 5 min extraction time per a cycle were used for extraction of studied compounds from one sample. The extraction vessel and connection capillaries were rinsed for $20 \mathrm{~s}$ with DCM after extraction and subsequently purged for 1 min with pure nitrogen. Sample extraction was finished in about half an hour and the total volume of extract obtained under those conditions was about $25 \mathrm{~mL}$. Extracts were collected into $40 \mathrm{~mL}$ glass vials. The extraction solvent was evaporated by rotary vacuum evaporation (RVE) at $30{ }^{\circ} \mathrm{C}$ to dryness and evaporation residue was redissolved in $1 \mathrm{~mL}$ of hexane or cyclohexane. Spiked real samples were used to investigate the clean-up procedure to determine the most relevant method for accurate results acquisition. The samples were spiked with 500 ng of each target nitroPAHs. Spiking solution was prepared in methanol.

\section{Extract fractionation}

Open column chromatography was performed on a 250 $\times 10 \mathrm{~mm}$ i.d. glass column (Merci, Czech Republic) filled with $5 \mathrm{~g}$ of fully activated silica gel. The top of the silica gel bed was covered with $1 \mathrm{~g}$ of dried anhydrous sodium sulphate. The silica gel column was washed with $10 \mathrm{~mL}$ of hexane (nC6) before raw extract application. $500 \mu \mathrm{L}$ of redissolved extract was applied on the top of this column in each fractionation experiment. The fractionation was performed with the aim to separate compounds in the extract into the four fractions-nonpolar, aromatic, slightly aromatic and polar. The influence of solvent nature used for redissolving of the evaporation residue obtained from RVE was formerly investigated. Cyclohexane (cC6) and hexane were found as suitable solvents for the application of extract on the fractionation column filled with silica gel. ${ }^{16}$

Normal phase liquid chromatographic separation can be affected by amount of nonpolar solvent or solvents with lower elution strength. Different total volumes of hexane $(15,20$ and $25 \mathrm{~mL}$ ) and different ratio of hexane and DCM in their mixture $(1: 1$ and $4: 1, \mathrm{v} / \mathrm{v})$ were investigated for the elution of target fractions. The total volume of the mixture of hexane and DCM used for elution of aromatic fraction, applied in 5 $\mathrm{mL}$ portions, was $15 \mathrm{~mL}$. The slightly aromatic fraction was eluted by $10 \mathrm{~mL}$ of DCM and the polar fraction was eluted by $10 \mathrm{~mL}$ of $\mathrm{MeOH}$. Portions of 5 or $10 \mathrm{~mL}$ of elution solvents were collected, evaporated to dryness, redissolved in $200 \mu \mathrm{L}$ of isooctane solution of $\mathrm{HCB}\left(0.476 \mu \mathrm{g} \mathrm{mL}^{-1}\right.$ the same concentration as in the calibration solution) and were analysed by GC-MS operated in SCAN mode.

The group of aromatic compounds consisted of 16 US EPA PAH (acenaphthene, acenaphthylene, anthracene, benz $[a]$ anthracene, benzo[ $b]$ fluoranthene, benzo $[k]$ fluoranthene, benzo[ghi]perylene, benzo[a]pyrene, dibenz $[a h]$ anthracene, fluoranthene, fluorene, chrysene, indeno[1,2,3-c,d]pyrene, naphthalene, phenanthrene, pyrene), 4H-cyclopenta[def]phenanthrene, dibenzofuran, 1-phenylnaphthalene, 2-methylanthracene, 5-methylchrysene, 2-methylphenanthrene, 1-methylnaphthalene, 2-methylnaphthalene, 1-methylpyrene. The group of slightly polar compounds consisted of 9-nitroanthracene, 2-nitrofluorene, 6-nitrochrysene, 1-nitronaphthalene, 1-nitropyrene. The group of polar compounds consisted of anthracene-9,10-dione, 4H-cyclopenta[def]phenanthrene-4-one, dimethylanthracene9,10-dione, 9H-fluorene-9-one, methylantracene-9,10-dione.

\section{Gas Chromatography-Mass Spectrometry}

All analyses were performed by GC-MS using a Trio 1000 quadrupole mass spectrometer (Fisons Instruments, USA) equipped with a GC 8060 (Fisons Instruments, USA) gas chromatograph with split/splitless injector. GC conditions were optimised and were as follows: a DB-5MS capillary column $(5 \%$ phenyl-95\% polydimethylsiloxane; $30 \mathrm{~m} ; 0.25 \mathrm{~mm}$ i.d.; $0.25 \mu \mathrm{m}$ phase thickness-Agilent, USA); $2 \mathrm{~mL}$ splitless injection at $250{ }^{\circ} \mathrm{C}$; split valve was closed for $1 \mathrm{~min}$. Pure helium was used as carrier gas at the constant head pressure $150 \mathrm{kPa}$. The $\mathrm{GC}$ oven was temperature programmed: initial oven temperature $90^{\circ} \mathrm{C}$, held for $1 \mathrm{~min}$; then increased at $25^{\circ} \mathrm{C} \min ^{-1}$ to $180{ }^{\circ} \mathrm{C}$, then increased to $290{ }^{\circ} \mathrm{C}$ at $10^{\circ} \mathrm{C} \mathrm{min}^{-1}$ and held at this temperature for $25 \mathrm{~min}$.

The mass spectrometer was operated in the electron impact ionisation mode with the electron energy of 70 eV. MS was operated in SCAN mode (40-350 amu), for determination of nitro PAHs was operated in selected ion monitoring mode (SIM). Monitored ions were $\mathrm{M}^{+}$and $\mathrm{M}$ $30^{+}$. The MS interface temperature was $220^{\circ} \mathrm{C}$, The temperature of MS ion source $200{ }^{\circ} \mathrm{C}$. 


\section{Results and Discussion}

\section{Fractionation procedures}

The first possibility of improving the separation of fraction is the application of a higher volume of the nonpolar solvent for fraction elution. In this experiment, total volumes of hexane were changed from 15 to 25 $\mathrm{mL}$. Ratio of hexane and DCM mixture used in the second step was 1:1 (v/v). The contents of groups of compounds obtained in the individual fractions are shown in the Tables 1, 2 and 3. The compound contents are expressed as percentages of their total amounts found.

Table 1. Content of groups of compounds in each fraction in \%; total hexane volume: $15 \mathrm{~mL}$

\begin{tabular}{|c|c|c|c|c|c|c|c|c|c|}
\hline & \multirow{2}{*}{$\begin{array}{c}\text { Solvent } \\
\text { Volume }^{\# / m L}\end{array}$} & \multicolumn{2}{|c|}{$\mathrm{nC} 6$} & \multicolumn{3}{|c|}{$\begin{array}{c}\text { nC6:DCM } \\
1: 1\end{array}$} & \multicolumn{2}{|c|}{ DCM } & \multirow{2}{*}{$\begin{array}{c}\text { DCM:MeOH } \\
1: 1 \\
10\end{array}$} \\
\hline & & 10 & 5 & 5 & 5 & 5 & 5 & 5 & \\
\hline \multirow[t]{5}{*}{ nC6* } & Fraction & & & & & & & & \\
\hline & Nonpolar & 100 & 0 & 0 & 0 & 0 & 0 & 0 & 0 \\
\hline & Aromatic & 0 & 0 & 32 & 68 & 0 & 0 & 0 & 0 \\
\hline & Sl polar & 0 & 0 & 0 & 73 & 27 & 0 & 0 & 0 \\
\hline & Polar & 0 & 0 & 0 & 4 & 6 & 64 & 26 & 0 \\
\hline \multicolumn{10}{|l|}{ cC6* } \\
\hline & Nonpolar & 93 & 7 & 0 & 0 & 0 & 0 & 0 & 0 \\
\hline & Aromatic & 0 & 0 & 6 & 92 & 2 & 0 & 0 & 0 \\
\hline & Sl polar & 0 & 0 & 0 & 43 & 56 & 1 & 0 & 0 \\
\hline & Polar & 0 & 0 & 0 & 2 & 1 & 43 & 54 & 1 \\
\hline
\end{tabular}

"Extracts were applied on silica gel column dissolved in nC6 or cC6. "Volume of individual elution step. S1 polar: Slightly polar fraction.

Table 2. Content of groups of compounds in each fraction in \%; total hexane volume: $20 \mathrm{~mL}$

\begin{tabular}{|c|c|c|c|c|c|c|c|c|c|c|}
\hline & \multirow{2}{*}{$\begin{array}{c}\text { Solvent } \\
\text { Volume } / \mathrm{mL}\end{array}$} & \multicolumn{3}{|c|}{ nC6 } & \multicolumn{3}{|c|}{$\begin{array}{c}\text { nC6:DCM } \\
1: 1\end{array}$} & \multicolumn{2}{|c|}{ DCM } & \multirow{2}{*}{$\begin{array}{c}\text { DCM:MeOH } \\
1: 1 \\
10\end{array}$} \\
\hline & & 10 & 5 & 5 & 5 & 5 & 5 & 5 & 5 & \\
\hline \multirow[t]{5}{*}{ nC6* } & Fraction & & & & & & & & & \\
\hline & Nonpolar & 100 & 0 & 0 & 0 & 0 & 0 & 0 & 0 & 0 \\
\hline & Aromatic & 0 & 0 & 20 & 28 & 52 & 0 & 0 & 0 & 0 \\
\hline & S1 polar & 0 & 0 & 0 & 0 & 74 & 26 & 0 & 0 & 0 \\
\hline & Polar & 0 & 0 & 0 & 0 & 6 & 3 & 57 & 32 & 2 \\
\hline \multicolumn{11}{|l|}{$\mathrm{cC} 6^{*}$} \\
\hline & Nonpolar & 89 & 11 & 0 & 0 & 0 & 0 & 0 & 0 & 0 \\
\hline & Aromatic & 0 & 0 & 23 & 23 & 52 & 2 & 0 & 0 & 0 \\
\hline & S1 polar & 0 & 0 & 0 & 0 & 58 & 42 & 0 & 0 & 0 \\
\hline & Polar & 0 & 0 & 0 & 0 & 1 & 14 & 55 & 30 & 0 \\
\hline
\end{tabular}

*Extracts were applied on silica gel column dissolved in nC6 or cC6. "Volume of individual elution step. S1 polar: Slightly polar fraction.

Table 3. Content of groups of compounds in each fraction in \%; total hexane volume: $25 \mathrm{~mL}$

\begin{tabular}{|c|c|c|c|c|c|c|c|c|c|c|c|}
\hline & \multirow{2}{*}{$\begin{array}{c}\text { Solvent } \\
\text { Volume }^{\#} / \mathrm{mL}\end{array}$} & \multicolumn{4}{|c|}{$\mathrm{nC} 6$} & \multicolumn{3}{|c|}{$\begin{array}{c}\text { nC6:DCM } \\
1: 1\end{array}$} & \multicolumn{2}{|c|}{ DCM } & \multirow{2}{*}{$\begin{array}{c}\text { DCM:MeOH } \\
1: 1 \\
10\end{array}$} \\
\hline & & 10 & 5 & 5 & 5 & 5 & 5 & 5 & 5 & 5 & \\
\hline \multirow[t]{5}{*}{ nC6* } & Fraction & & & & & & & & & & \\
\hline & Nonpolar & 100 & 0 & 0 & 0 & 0 & 0 & 0 & 0 & 0 & 0 \\
\hline & Aromatic & 0 & 0 & 24 & 31 & 45 & 0 & 0 & 0 & 0 & 0 \\
\hline & Sl polar & 0 & 0 & 0 & 0 & 7 & 92 & 1 & 0 & 0 & 0 \\
\hline & Polar & 0 & 0 & 0 & 0 & 0 & 11 & 49 & 40 & 0 & 0 \\
\hline \multicolumn{12}{|l|}{ cC6* } \\
\hline & Nonpolar & 92 & 8 & 0 & 0 & 0 & 0 & 0 & 0 & 0 & 0 \\
\hline & Aromatic & 0 & 0 & 8 & 15 & 68 & 9 & 0 & 0 & 0 & 0 \\
\hline & S1 polar & 0 & 0 & 0 & 0 & 8 & 90 & 2 & 0 & 0 & 0 \\
\hline & Polar & 0 & 0 & 0 & 0 & 0 & 4 & 74 & 22 & 0 & 0 \\
\hline
\end{tabular}

*Extracts were applied on silica gel column dissolved in nC6 or cC6. "Volume of individual elution step. Sl polar: Slightly polar fraction. 
The nonpolar fraction was separated from the other fractions in all experiments. The separation of aromatic, slightly polar and polar fraction from each other was improved with increasing volume of $\mathrm{nC} 6$ on the beginning of elution. In spite of this, complete separation was not achieved. The amount of the compounds that were not separated from the previous eluted fraction was in the order of $5-10 \%$ in each fraction.

There were no significant differences in the separations of the four investigated groups of compounds whether whether hexane or cyclohexane was used for extract redissolving before applying on the silica gel column. The following experiments were performed with cyclohexane because of its better ability to dissolve residues of evaporated extracts. Different mixtures of nC6 with DCM were examined for the best separation of fractions. Using the mixture of nC6 with DCM in volumetric ratio 4 to 1 improved the elution of the aromatic fraction. Total volume of hexane used for nonpolar compounds elution was 10 $\mathrm{mL}$ in the first experiment and $15 \mathrm{~mL}$ in the second experiment. Contents of groups of compounds obtained in individual fractions are shown in the Tables 4 and 5. The compound contents are expressed as percentages of their total amounts found.

The lower content of DCM in the mixture caused its lower elution strength. A better separation of compounds of the aromatic fraction from compounds of the slightly polar fraction was achieved. The slightly polar fraction still coeluted with the polar fraction, however, it does not matter in case of nitro PAHs analysis. Compounds of the polar fraction occur in the samples in similar concentration levels as nitro-PAHs and are separated from them on GC column. The difficulties appear in the presence of polycyclic aromatic hydrocarbons, whose concentrations are often higher by several orders of magnitude. Due to the high amount of PAHs in the samples it was not possible to analyse nitro-PAHs and other minor components in the presence of PAHs. The fractionation of raw extracts was necessary.

The most effective fractionation procedure was as follows: Fraction 1 was eluted by $10 \mathrm{~mL}$ of $\mathrm{nC} 6$ and then by $5 \mathrm{~mL}$ of $\mathrm{nC} 6: \mathrm{DCM} 4: 1(\mathrm{v} / \mathrm{v})$, fraction 2 was eluted by $10 \mathrm{~mL}$ of nC6:DCM 4:1 (v/v), fraction 3 was eluted by $10 \mathrm{~mL}$ of DCM, fraction 4 was eluted by $10 \mathrm{~mL}$ of DCM:MeOH 1:1 (v/v). The chromatograms are shown in the Figure 1.

Table 6 shows the average contents of groups of compounds in each fraction obtained at the fractionation conditions written above. Three fractionation procedures were carried out.

All fractions are fully separated from each other except fraction 3 that contains a small amount of compounds from next fraction (more polar compounds). This separation is sufficient for analysis of nitro-PAHs in a soil and dust samples.

Table 4. Content of groups of compounds in each fraction in $\%$

\begin{tabular}{|c|c|c|c|c|c|c|c|c|}
\hline \multirow{2}{*}{$\begin{array}{l}\text { Solvent } \\
\text { Volume }^{\#} / \mathrm{mL}\end{array}$} & \multirow{2}{*}{$\begin{array}{r}\mathrm{nC6} \\
10\end{array}$} & \multicolumn{3}{|c|}{$\begin{array}{c}\text { nC6:DCM } \\
4: 1\end{array}$} & \multicolumn{2}{|c|}{ DCM } & \multicolumn{2}{|c|}{$\begin{array}{c}\text { DCM:MeOH } \\
1: 1\end{array}$} \\
\hline & & 5 & 5 & 5 & 5 & 5 & 10 & 5 \\
\hline \multicolumn{9}{|l|}{ Fraction } \\
\hline Nonpolar & 96 & 4 & 0 & 0 & 0 & 0 & 0 & 0 \\
\hline Aromatic & 0 & 0 & 9 & 90 & 1 & 0 & 0 & 0 \\
\hline Sl polar & 0 & 0 & 0 & 0 & 8 & 92 & 0 & 0 \\
\hline Polar & 0 & 0 & 0 & 0 & 0 & 14 & 86 & 0 \\
\hline
\end{tabular}

Extracts were applied on silica gel column dissolved in cC6. "Volume of individual elution step. Sl polar: Slightly polar fraction.

Table 5. Content of groups of compounds in each fraction in $\%$

\begin{tabular}{|c|c|c|c|c|c|c|c|c|c|}
\hline \multirow{2}{*}{$\begin{array}{l}\text { Solvent } \\
\text { Volume }^{\# / \mathrm{mL}}\end{array}$} & \multicolumn{2}{|c|}{ nC6 } & \multicolumn{3}{|c|}{$\begin{array}{c}\text { nC6:DCM } \\
4: 1\end{array}$} & \multicolumn{2}{|c|}{ DCM } & \multicolumn{2}{|c|}{$\begin{array}{c}\text { DCM:MeOH } \\
1: 1\end{array}$} \\
\hline & 10 & 5 & 5 & 5 & 5 & 5 & 5 & 10 & 5 \\
\hline \multicolumn{10}{|l|}{ Fraction } \\
\hline Nonpolar & 97 & 3 & 0 & 0 & 0 & 0 & 0 & 0 & 0 \\
\hline Aromatic & 0 & 0 & 0 & 0 & 100 & 0 & 0 & 0 & 0 \\
\hline S1 polar & 0 & 0 & 0 & 0 & 0 & 11 & 89 & 0 & 0 \\
\hline Polar & 0 & 0 & 0 & 0 & 0 & 0 & 9 & 91 & 0 \\
\hline
\end{tabular}

Extracts were applied on silica gel column dissolved in cC6. ${ }^{*}$ Volume of individual elution step. Sl polar: Slightly polar fraction. 

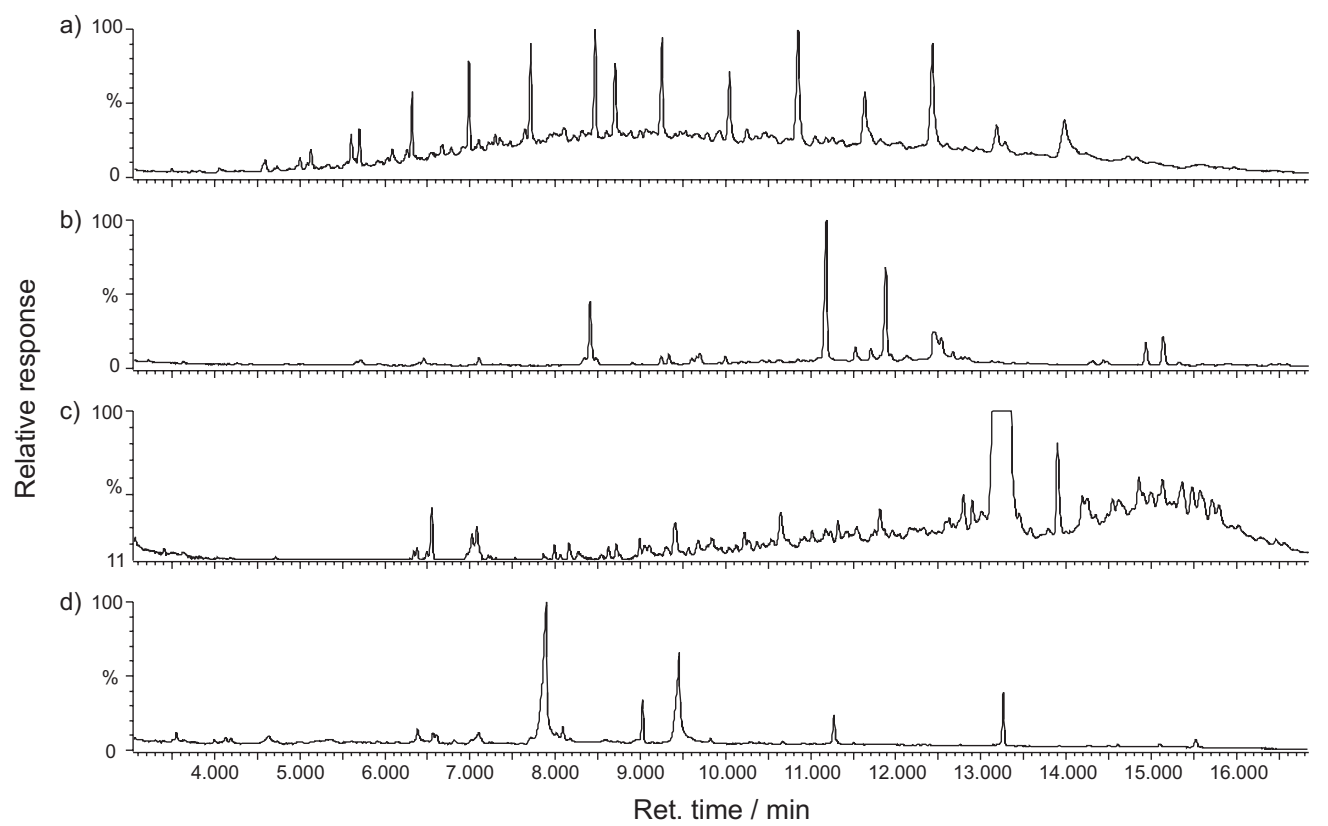

Figure 1. Chromatograms of individual fractions obtained from roadside dust extract. (a) nonpolar fraction, (b) aromatic fraction, (c) slightly polar fraction, (d) polar fraction.

Table 6. Average content of groups of compounds in each fraction obtained by the final procedure

\begin{tabular}{lcccc}
\hline Fraction & $\begin{array}{c}\text { Fraction 1 } \\
\%\end{array}$ & $\begin{array}{c}\text { Fraction 2 } \\
\%\end{array}$ & $\begin{array}{c}\text { Fraction 3 } \\
\%\end{array}$ & $\begin{array}{c}\text { Fraction 4 } \\
\%\end{array}$ \\
\hline Nonpolar & 100 & 0 & 0 & 0 \\
Aromatic & 0 & 99 & 1 & 0 \\
Slightly polar & 0 & 0 & 100 & 0 \\
Polar & 0 & 0 & 6 & 94 \\
\hline
\end{tabular}

\section{Analysis of nitro-PAHs in soil and dust samples}

The final optimised method used for determination of nitro-PAHs in soil or dust samples was as follows. About $2 \mathrm{~g}$ of sample was mixed with $3 \mathrm{~g}$ of anhydrous sodium sulphate. The mixture was PSE extracted under the conditions mentioned above. Extraction solvent was evaporated and the residue was dissolved in $1 \mathrm{~mL}$ of cyclohexane. $500 \mu \mathrm{L}$ of this solution was fractionated using final fractionation procedure. Fractions 1, 2 and 4 were discarded and fraction 3 was evaporated and redissolved in $200 \mu \mathrm{L}$ of isooctane solution of HCB $\left(0.476 \mu \mathrm{g} \mathrm{mL}^{-1}\right)$ and were analysed by GC-MS operated in SIM mode. A method of standard addition was used for the recovery determination. Unspiked and spiked samples were analysed in triplicate.

Limits of detection (LOD) varied from 50 to $220 \mathrm{pg}$ of nitro-PAHs in injection. These values and also limits of quantification (LOQ) were calculated according to the EURACHEM guide. ${ }^{17}$ Table 7 shows LOD, LOQ and recoveries of target nitro-PAHs and relative standard deviations (RSD) obtained from an analytical procedure used for their determination. Lower recoveries of 1-nitronaphthalene and 2-nitrofluorene may be caused by their higher volatility. They are probably lost during the evaporation steps.

No target nitro PAHs were found in the analysed soil samples. Significant amount of 1-nitropyrene $(37 \pm 6 \mu \mathrm{g}$ $\mathrm{kg}^{-1}$ ) was determined in the roadside dust. Other target nitro-PAHs were not found.

Table 7. Limit of detection (LOD), limit of quantification (LOQ), amount (detected in the roadside dust) of nitro PAHs and their values of recovery

\begin{tabular}{|c|c|c|c|c|c|}
\hline Compound & $\begin{array}{c}\text { LOD } \\
\text { pg }\end{array}$ & $\begin{array}{c}\text { LOQ } \\
\text { pg }\end{array}$ & $\begin{array}{c}\text { Concentration } \\
\mu \mathrm{g} \mathrm{kg}^{-1}\end{array}$ & $\begin{array}{c}\text { Recovery } \\
\%\end{array}$ & $\begin{array}{c}\mathrm{RSD} \\
\%\end{array}$ \\
\hline 1-nitronaphthalene & 50 & 150 & n.d. & 65 & 14 \\
\hline 2-nitrofluorene & 175 & 525 & n.d. & 60 & 18 \\
\hline 9-nitroanthracene & 80 & 240 & n.d. & 79 & 13 \\
\hline 1-nitropyrene & 85 & 225 & 37 & 81 & 16 \\
\hline 6-nitrochrysene & 220 & 660 & n.d. & 108 & 10 \\
\hline
\end{tabular}

pg: injected into GC; n.d.: not detected. 


\section{Conclusions}

A fractionation step following liquid extraction is required to decrease chemical the background and to separate minority compounds (derivatives of PAHs) from parent PAHs. Silica gel column chromatography with fully activated silica gel (5 g) was chosen for that purpose. The optimisation of a set of solvents used for the elution of compounds was performed with the aim to find the best solvent system that is able to separate nitro-PAHs from parent PAHs. To achieve maximum preparation performance the use of solvents with lower elution strengh (nC6:DCM 4:1, v/v) is required. An improved separation of the aromatic fraction and slightly polar fraction was achieved, compared with nC6:DCM 1:1 (v/v) mixture. Although the slightly polar and polar fraction still partially coelute, this procedure is sufficient for analysis of nitro PAHs.

\section{Acknowledgments}

This research was partially supported by the project of Ministry of Agriculture Czech Republic MZE 0002716201 and project of Ministry of Education, Youth and Sports Czech Republic MSM 0021622412.

\section{References}

1. Esteve, W.; Budzinski, H.; Villenave, E.; Atmos. Environ. 2006, 40, 201.

2. Ritter, C.L.; Culp, S.J.; Freeman, J.P.; Marques, M.M.; Beland, F.A.; Malejka-Giganti, D.; Chem. Res. Toxicol. 2002, 15, 536.
3. Horikawa, K.; Será, N.; Murakami, K.; Sano, A.; Izumi, K.; Tokiwa, H.; Toxicol. Lett. 1998, 98, 51.

4. Gupta, P.; Harger, W.P.; Arey, J.; Atmos. Environ. 1996, 30, 3157.

5. Durant, J.L.; Busby, W.F.; Lafleur, J.A.L.; Penman, B.W.; Crespi, Ch.L.; Mutat. Res. 1996, 371, 123.

6. Hecht, S.S.; Environ. Mol. Mutagen. 2002, 39, 119.

7. Enya, T.; Suzuki, H.; Watanabe, T.; Hirayama, T.; Hisamatsu, Y.; Environ. Sci. Technol. 1997, 31, 2772.

8. Lewtas, T.; Int. J. Environ. Anal. Chem. 1990, 39, 245.

9. Bamford, H.A.; Bezabeh, D.Z.; Schantz, M.M.; Wise, S.A.; Baker, J.E.; Chemosphere 2003, 50, 575.

10. Becker, G.; Colmsjö, A.; Östman, C.; Environ. Sci. Technol. 1999, 33, 1321.

11. Zielinska, B.; Sagebiel, J.; McDonald, J.D.; Whitney, K.; Lawson, D.R.; J. Air Waste Manage. Assoc. 2004, 54, 1138.

12. Meyer, S.; Cartellieri, S.; Steinhart, H.; Anal. Chem. 1999, 71, 4023.

13. Cecinato, A.; Mabilia, R.; Marino, F.; Atmos. Environ. 2000, 34, 5061.

14. Wingfors, H.; Sjödin, A.; Haglund, P.; Brorström-Lundén, E.; Atmos. Environ. 2001, 35, 6361.

15. Carlsson, H.; Östman, C.; J. Chromatogr., A 1997, 790, 73.

16. Prycek, J.; Ciganek, M.; Simek, Z.; J. Chromatogr., A 2004, 1030, 103.

17. Holcombe, D.; The Fitness for Purpose of Analytical Methods: A Laboratory Guide to Method Validation and Related Topics, LGC: Middlesex, 1998.

Received: September 11, 2006 Web Release Date: August 23, 2007 